\title{
Urgences
}

\section{Lanternes vacillantes (illustrations de Myriam Ol'Sommer)}

\section{Jean Cossette}

Numéro 4, 2e trimestre 1982

URI : https://id.erudit.org/iderudit/025058ar

DOI : https://doi.org/10.7202/025058ar

Aller au sommaire du numéro

Éditeur(s)

Urgences

ISSN

0226-9554 (imprimé)

1927-3924 (numérique)

Découvrir la revue

Citer ce document

Cossette, J. (1982). Lanternes vacillantes (illustrations de Myriam Ol'Sommer).

Urgences, (4), 41-50. https://doi.org/10.7202/025058ar d'utilisation que vous pouvez consulter en ligne.

https://apropos.erudit.org/fr/usagers/politique-dutilisation/ 


\section{JEAN COSSETTE}

\section{Lanternes vacillantes}

(Illustrations de Myriam 0l'Sommer) 


\section{SOMNOLENCE}

Vierges folles aux tuniques kaki, quand donc chasserez-vous:

l'éclat des lumières sur les flancs délavés

les longs et grands gémissements des grises symphonies de l'automne et ces mots qui tombent, des blanches et des noires sur le sol, dans les antres des trombones

le plomb et la berge près du navire fantôme et ces rats d'ennui

ce trou dans la neige comme une île enfoncée dans sa marée de glace

la fumée du haut de ces rondes cheminées vers les ouates gonflées

l'écran magique des sous-bois d'octobre et de novembre

l'oubli des mots, l'oubli des sens, au-delà des réverbères, des faîtes et des nuages, dans la densité de liberté et l'extase d'existence

ces deux monocles tournant sur l'axe des dieux

ces grands enfants, les mains sur les yeux, les dents hors des lèvres, qui écoutent en silence devant la mer en feu l'oratorio des mouettes chauves 
le sourd dans sa chambre sans musique et la profondeur du soir où l'âge de I'homme compte ses vieilles reliques

la pluie sur ma vitre grise et ses yeux au plafond de mes jours heureux

la vie de la mort où les spectres dansent

I'hiver qui fait place à I'hiver pendant qu'elle attend toujours seule sous son toit avec les ombres

les cris des longs oiseaux en des plaintes confuses sur nos rives d'espoirs muets

les pavés lavés des encres uniformes

I'ennui dans nos sabots de cèdre au bras d'éternels menuets

Comment prendre à parti I'univers infécond des drames sans suite

De quel pays me parlez-vous quand le mien est ici, dans ce grand lit de neige aux ailes d'oiseaux

Sachez que j'ai le coeur chaud comme le poêle en braise. 


\section{LANTERNES VACILLANTES}

Quand les heures s'étonnent d'être si caressantes en ce basquartier, je couche sur les trottoirs les phrases, les pas et les silences de mes forêts intérieures.

J'avance yeux mi-clos vers l'appel des oies sauvages, toujours plus au sud dans l'orange des sables mûrs.

Toutes les nuits jusqu'à l'aube, lorsque le cercle de feu se lève derrière ta nuque tiède, d'un flanc à l'autre je voyage à voile sur l'océan de tes seins.

Alors qu'en dedans de moi se jouent les armes et les colombes, je viens d'espoir te chercher pour ramener à mon lit deux tresses blanches sur l'oreiller des indépendances.

Parfois les portes s'entrouvent comme des charnières et les mots s'évadent. J'incite l'écho à se répondre dans ce demi-néant des longs passages opaques. 

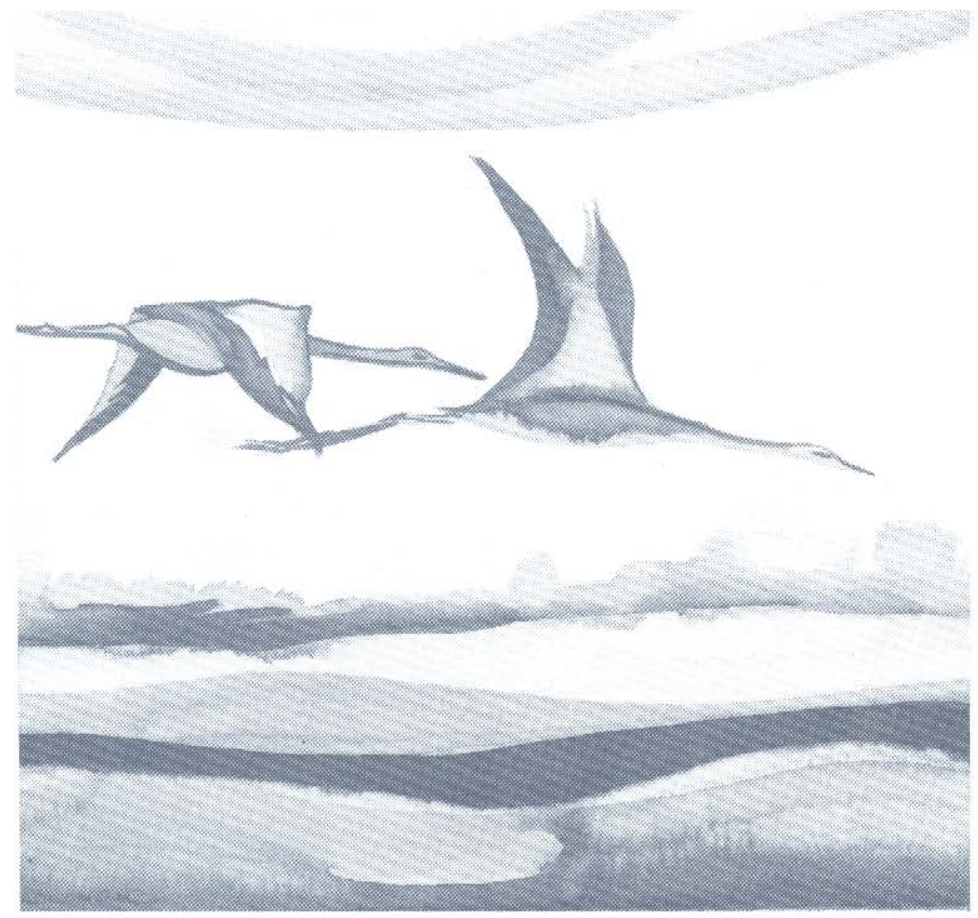

"J'avance yeux mi-clos vers l'appel des oies sauvages."

(Lanternes vacillantes) 
Je verse la nuit sur les asphaltes coulants. Je rends l'attente plus captive d'elle-même. Le je s'épuise de n'être que soi.

Je laisse voguer dans ma tête un beau navire très ému, comme celui de mes prières, un peu chancelant, vers ce grand remous d'aimer.

Je sombre à l'envers de moi pour m'infiltrer dans le tréfonds des rois nègres. Je rêve à une délivrance bleue champêtre, moi qui cueille des fleurs pour revivre tes mains, toi vers qui je tends les bras comme pour appeler le silence.

Au travers des champs sublimes, au centre d'un lit blême et lilas cafard, je les navigue tes bateaux, pour m'en délivrer au jour des repos continus.

De l'espoir du soir au chagrin du matin, je voyage d'image en image, oubliant le temps, le son des transitions. 


\section{LE TRANSIT DES FÉES}

La vie s'éparpille dans le trop plein de ses paupières, dans I'angoisse longue de ses heures courtes

Les orgues ne sont plus que ce souffle léger, le jour du fond de la nef, le soir du haut de la crypte

et l'on va son chemin sans retourner la tête vers ces retours incertains, et I'on avance un peu plus sans penser à l'ombre qui nous suit

Tout se dilate, le temps avec lequel on a joué sans trop y prêter attention

On penche vers le soir, on s'évade par le chemin des étoiles, notre bouche à la terre salive pour payer les instants et les baisers de nos circonférences unies

Pendant que la chatte nous regarde de ses longs yeux langoureux, les coussins se pressent et ronronnent tant et aussi longtemps que l'heure s'attache au pendule

Dans la quête des enfants foisonnent des rêves à la mesure de nos embarcations alors que nous sommes à attendre la descente de l'heure, à la minuit ou au levant, peu importe, le temps ne 
change que les gens et la mer est si grande dans son dortoir ensommeillé

Où passent les silences à n'espérer que des chimères...

Nous sommes des oiseaux aux ailes ouvertes dans un dernier envol vers l'au-delà de nos rêves

J'ai le mal de l'infini temporel

Pouvoir enfin prendre conscience de soi comme prendre conscience de la mort quand elle nous devance, en ces chambres où les nuits s'abandonnent en des songes délicats, où le repos semble se complaire de fantasmes et d'encens

Là-bas, la lune se reflétant sur l'océan d'argile, de nouveau froissée par la marée sans âge, dessine de longues coulées de lumière offrant aux océanides des lanternes, celles-là qui glissent secrètement sous le soir vagabond

Ailleurs, I'herbe à nos pieds se traîne et en nos têtes, neige d'aube, neige du souvenir attisé, pendant que dans l'antichambre du désir l'homme s'émerveille déjà devant son miroir de paille, 


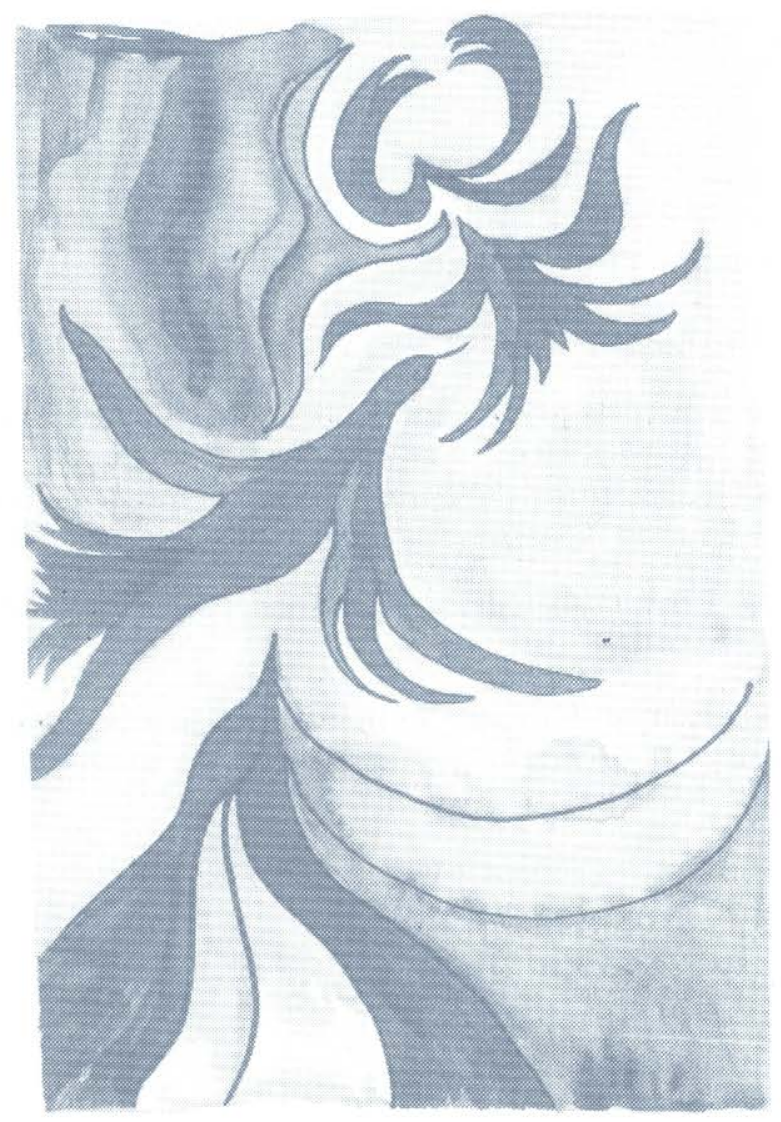

"Nous sommes des oiseaux aux ailes ouvertes dans un dernier envol vers l'au-delà de nos rêves."

(Le transit des fées) 
alors que jonglent les fourmis dans sa tête.

Est-il vain d'entretenir des chimères...

Si les hautes herbes du côté des parloirs font l'amour, les rivages reviennent, beiges et bleus, avec des envies de dormir.

Les portes basculantes du désir se sont fermées au bout du champ de feu, dans le comble des mirages et des rendez-vous abstraits

Ce n'est plus tant la solitude que l'absence, l'espace second entre l'imagerie et l'extase

Je quitte la clameur fumigène et me laisse digérer lentement par le nocturnal d'outre-présence pour déposer mon vote de nacre dans ton urne de chair

De fragiles oiseaux gagnent le large inexorablement. 